\title{
NEW THEORY TO PREDICT THE ELASTIC MODULUS OF CARBON NANOTUBE BASED-COMPOSITES
}

\author{
Naser Kordani ${ }^{1 *}$, Ali Sadough Vanini ${ }^{2}$, Rezvan Adibipour $^{2}$ \\ ${ }^{1}$ Department of Mehanical Engineering, University of Mazandaran, Iran \\ ${ }^{2}$ Department of Mehanical Engineering, Amirkabir University of Technology, \\ Tehran, Iran
}

[Received: 27 November 2018. Accepted: 21 October 2019]

doi: 10.7546/JTAM.49.19.04.04

\begin{abstract}
The relatively weak mechanical properties of polymer have prevented its application in the components which demand high mechanical strength and stability. There are numerous theories with special assumption on the mechanics of nanocomposite to predict the elastic modulus. However, some of these theories can be efficient to consider the influences of CNTs on elastic properties of nanocomposite reinforced CNTs. Current research focuses on creation a new model base on new assumption with just having single fiber to predict the elastic modulus of nanocomposite reinforced CNTs. To verify the predictions of the new model we used experimental data and some well-known theories. Errors at most of the models were more than $10 \%$, while by using this new model, errors has been decreased.
\end{abstract}

KEY WORDS: Carbon Nanotubes, Mechanical Properties of Nanocomposites, Polymer Matrix Composites, Elastic Modulus, Nanocomposite Modeling.

\section{INTRODUCTION}

Nanocomposite is a mixture of two distinct constituents, reinforcement and matrix, with remarkably different properties [1-4]. Recently, nanoparticles have been attracting increasing attention in the composite community because they are capable of improving the mechanical and physical properties of traditional fiber reinforced composites [5-9]. CNTs have many structures, Multi-walled carbon nanotubes (MWNTs) and single-walled carbon nanotubes (SWNTs) which are the most well-known type of CNTs. In 1991, MWNTs consist of many coaxial graphite cylindrical tubes and in 1993; Sumio Iijima discovered SWNTs with one graphite cylindrical tube [10]. MWCNTs and SWCNTs were discovered in soot of arc-discharge method and using metal catalysts in arc-discharge method [11,12]. Polymer matrixes generally combine high-strength, high-stiffness fibers (CNT, kevlar, etc.) with lowdensity matrix materials (epoxy, polyvinyl, etc.). The relatively weak mechanical properties of polymer have prevented its application in CNTs with the outstanding

\footnotetext{
${ }^{*}$ Corresponding author e-mail: naser.kordani@umz.ac.ir
} 
elastic modulus of $1 \mathrm{TPa}$, tensile strength of $63 \mathrm{GPa}$ and high aspect ratio are among the strongest and stiffest reinforcements. The notable mechanical properties make CNTs to become one of the most intensively studied materials and ideal choice as reinforcement in metal, polymer and ceramic matrix nanocomposites [13-16].

There have been numerous theories and well-known models with special assumption on the mechanics of nanocomposite to predict the elastic modulus such as (HalpinTsai equation, shear lag, etc.). Halpin and Tsai were presented an equation that is efficient to predict the modulus values for the fiber reinforced composite samples; now Halpin-Tsai equation is used to predict the elastic modulus of nanocomposite reinforced CNTs [17-19].

Researchers have modified the Halpin-Tsai equation. Cox proposed an orientation factor parameter to account the randomness of discontinuous fibers [20]. Meng et al. used the orientation factor to obtain the effective elastic modulus of CNTs to modify the Halpin-Tsai equation [21]. At the nanoscale, the structure of the carbon nanotube strongly effects on the properties of composite. Thostenson and Chou developed a fundamental understanding effect of the CNTs structure on the elastic properties of nanotube-based composites. They used Halpin-Tsai equation through modifying the micromechanical approach to model short fibre composites to the account for the structure of the nanotube reinforcement to predict the elastic modulus of the nanocomposite as a function of the constituent properties, reinforcement geometry and nanotube structure. Their result shown that nanocomposite elastic properties are particularly sensitive to the nanotube diameter, since larger diameter nanotubes show a lower effective modulus and occupy a greater volume fraction in the composite related to smaller-diameter nanotubes [22]. And base on filler, there is further modification of the Halpin-Tsai equation by using different shape factor [21-23].

Shear lag theory have been used to consider the effect of the aspect ratio on elastic properties of nanocomposites reinforced CNTs [24]. In considering the elastic properties of nanocomposite reinforced CNTs, other theories give result with high error.

Current research focuses on creating a new model base on new assumption with just having single fiber to predict the elastic modulus of nanocomposite reinforced CNTs. The correlation of the experimentally obtained elastic modulus showed a good agreement with this model.

\section{Methodology}

\subsection{HALPIN-TSAI MODEL}

The Halpin-Tsai equation has been recognized for its ability to predict the modulus values for the fiber reinforced composite samples. This equation was used to correlate 
the experimental findings. For convenience, the equations are shown below $[17,18]$ :

$$
\begin{aligned}
& E_{c}=E_{m}\left(\frac{1+(2 l / d) \eta v_{f}}{1-\eta v_{f}}\right), \\
& \eta=\frac{\frac{E_{f}}{E_{m}}-1}{\frac{E_{f}}{E_{m}}+\frac{2 l}{d}}
\end{aligned}
$$

where $E_{c}, E_{f}$ and $E_{m}$ are the modulus of composite, fiber (MWNT) and matrix, respectively. $v_{f}$ is the volume fraction of the fiber. $l$ and $d$ are the length and the diameter of CNT. The Halpin-Tsai equation was originally used for composites with unidirectional reinforcement.

\subsection{SHEAR LAG MODEL}

This model refines the law to predicting elastic modulus by introducing the effect of the filler aspect ratio. The equation of the elastic modulus of three-dimensional random short fiber composites is as follows [24]:

$$
E_{c}=E_{m}+v_{f}\left[\eta_{l} \eta_{T} E_{f}-E_{m}\right],
$$

$$
\eta_{l}=1 / 5, \quad \eta_{T}=1-\frac{\tanh (\beta r)}{\beta r}, \quad r=4 l / d, \quad \beta^{2}=\frac{2 \pi E_{m}}{E_{f}(1+\nu) \ln \left(1 / v_{f}\right)},
$$

where $\nu$ is the Poisson ratio of matrix, which is equal to 0.35 .

\subsection{NEW MODEL}

This model focuses on a single fiber of length $l$ and diameter $d$, which is encased in a concentric cylindrical shell of matrix. Length of outer cylinder and CNT are the same. The fiber is aligned parallel to the $x$-axis. Only the axial load $\mathrm{F}$ parallel to fiber is of interest (Fig. 1).

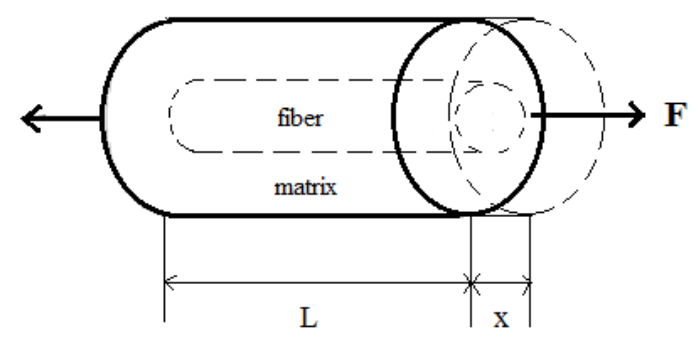

Fig. 1. The force on a cross-section of the nanocomposite element. 
We used a linear spring model instead of polymer matrix and CNT, as shown in Fig. 2.

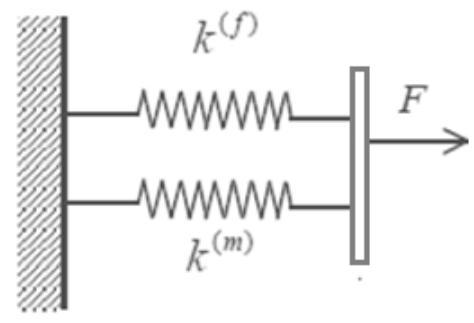

Fig. 2. Arrangement of CNT and matrix.

For this arrangement, loads are not equal

$$
F=F_{m}+F_{f}=F_{m}\left[1+\frac{F_{f}}{F_{m}}\right] .
$$

Here, $F_{f}$ and $F_{m}$ are the corresponding fiber load and matrix load. The equivalent stiffness of CNT and matrix for spring model in Fig. 2 can be obtained from Eq. 4.

$$
K_{i}=\frac{E_{i} A_{i}}{L_{i}} .
$$

$E_{i}, A_{i}$ and $L_{i}$ are elastic modulus, cross-section and length, respectively. In this study, the subscripts $f$ and $m$ refer to the fiber and matrix. Because of different properties of component, it can be assumed that the strains on the fibers and matrix in the loading direction are not same

$$
\epsilon_{f} \neq \epsilon_{m}
$$

and

$$
\epsilon_{m}=m \epsilon_{f},
$$

where $m$ is a constant that depends on fiber properties and fiber volume fraction. Using Hooke's law

$$
\frac{\sigma_{m}}{E_{m}}=m \frac{\sigma_{f}}{E_{f}} .
$$

Substituting $\sigma=F / A$ in Eq. 6

$$
\frac{F_{m}}{E_{m} A_{m}}=m \frac{F_{f}}{E_{f} A_{f}} .
$$


364 New Theory of the Elastic Modulus of Carbon Nanotube Based-Composites

Then,

$$
\frac{F_{f}}{F_{m}}=m \frac{E_{m} A_{m}}{E_{f} A_{f}} .
$$

Based on linear spring we have $F=k x$. Substituting in Eq. 3

$$
(k x)_{c}=(k x)_{m}\left[1+\frac{F_{f}}{F_{m}}\right] .
$$

We assumed that the displacement of matrix and composite are same,

$$
k_{c}=k_{m}\left[1+\frac{F_{f}}{F_{m}}\right] \text {. }
$$

Substituting Eq. 4 in Eq. 8

$$
\left(\frac{E A}{L}\right)_{c}=\left(\frac{E A}{L}\right)_{m}\left[1+\frac{F_{f}}{F_{m}}\right]
$$

Assuming that matrix and composite have equal length, then we obtained the elastic modulus of nanocomposite as follow:

$$
E_{c}=E_{m}\left(\frac{A_{m}}{A_{c}}\right)\left[1+\frac{F_{f}}{F_{m}}\right] .
$$

Volume fraction of matrix can be obtained from the following equation:

$$
v_{m, f}=\frac{V_{m, f}}{V_{c}}=\frac{A_{m, f} L}{A_{c} L}=\frac{A_{m, f}}{A_{c}},
$$

where $v_{m}, v_{f}$ and $V_{c}$ are the volume of matrix, CNTs and composite, respectively. The composite volume fraction is a function of the fiber weight fraction and the densities of the carbon fiber and the matrix [25]

$$
v_{f}=\frac{w_{f}}{w_{f}+\left(\frac{\rho_{f}}{\rho_{m}}\right)\left(1-w_{f}\right)},
$$

where $w_{f}$ is the nanotubes weight fraction, $\rho_{m}$ is the density of the matrix, $\rho_{f}$ is the density of fibers. Substituting Eq. 7 and Eq. 10 in Eq. 9,

$$
E_{c}=E_{m}\left(\frac{A_{m}}{A_{c}}\right)\left[1+\left(m \frac{E_{m} A_{m}}{E_{f} A_{f}}\right)^{-1}\right]=E_{m} v_{m}\left[1+\left(m \frac{E_{m} A_{m}}{E_{f} A_{f}}\right)^{-1}\right],
$$


where $m$ is a constant that depends on fiber properties and fiber volume fraction

$$
m=f\left(L_{f}, d, v_{f}\right) .
$$

Due to fit the suitable curve to the experimental data, we obtained this equation:

$$
m=c \frac{l}{d} v_{f}^{b},
$$

where $l$ is the length of fiber, $d$ - the average diameter of fiber, $b$ and $c$ are constants of Eq. 13, same for each nanocomposite, which is equal to 1.689. Trough substituting Eq. 13 in Eq. 12, the elastic modulus of composite is

$$
E_{c}=E_{m} v_{m}\left[1+\left(\left(c \frac{l}{d} v_{f}^{b}\right) \frac{E_{m} v_{m}}{E_{f} v_{f}}\right)^{-1}\right] .
$$

\section{Results AND Discussion}

Comparisons are performed between the predictions given this new model, HalpinTsai model, and experimental data reported by Montazeri [26], see Fig. 3.

For more comparison, we employed experimental results by Meng et al. [21]. The results are shown in Fig. 4.

Through predicting elastic modulus by using the Halpin-Tsai theory, results shown good agreement with experimental than shear lag theory. The Halpin-Tsai theory has high error in high MWNT weight percent. Through using this new model, results are

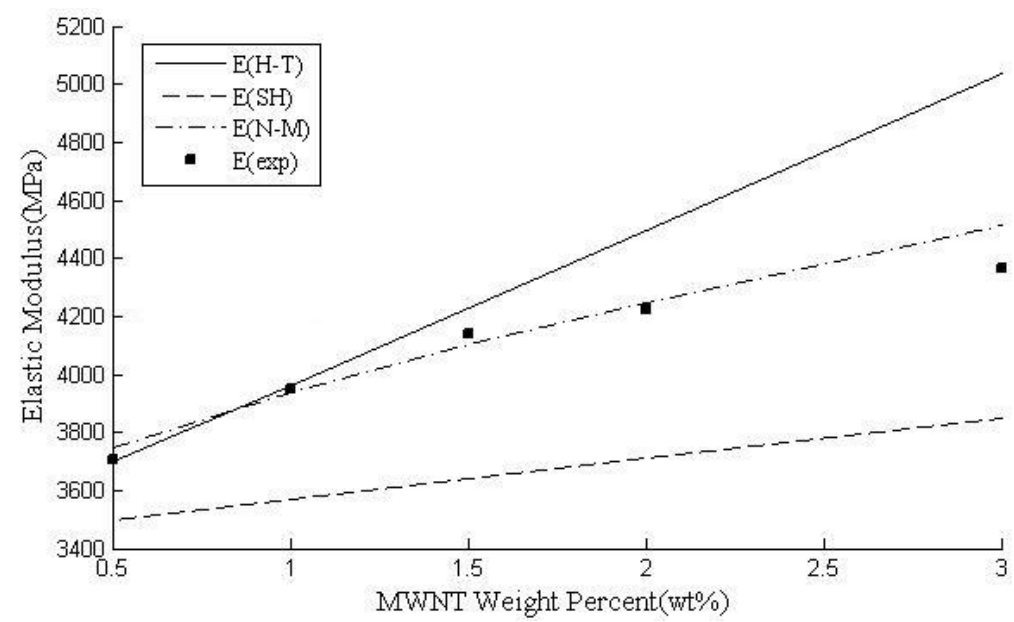

Fig. 3. Relation between elastic modulus of nanocomposite and MWNT weight percent, comparison among experimental data (exp) [26], Halpin-Tsai (H-T), new model (N-M), and shear lag ( $\mathrm{SH})$ theory. 
366 New Theory of the Elastic Modulus of Carbon Nanotube Based-Composites

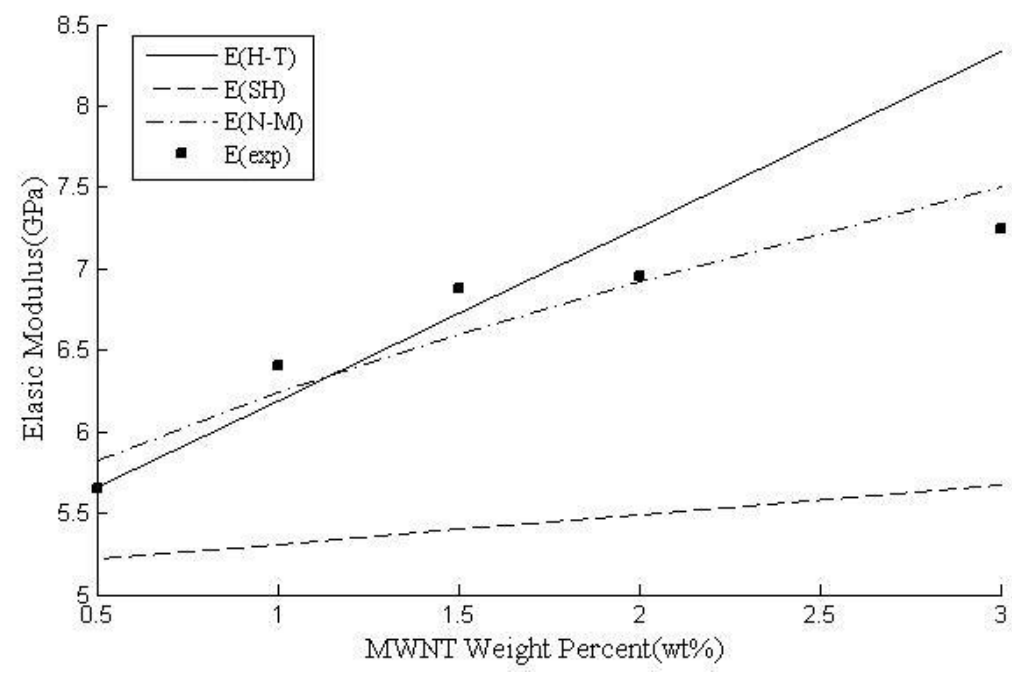

Fig. 4. Relation between elastic modulus of nanocomposite and MWNT weight percent, comparison among experimental data (exp) [26], Halpin-Tsai (H-T), new model (N-M), and shear lag (SH) theory.

improved and error had a decrease than the others in high weight percent. To consider the efficient of length, diameter and weight percent of CNTs on Elastic modulus of nanocomposite, the new model was used. As shown in Fig. 5. Increasing the elastic modulus of nanocomposite is related to increasing on CNTs weight percent and length of CNT and decreasing the diameter of CNT.

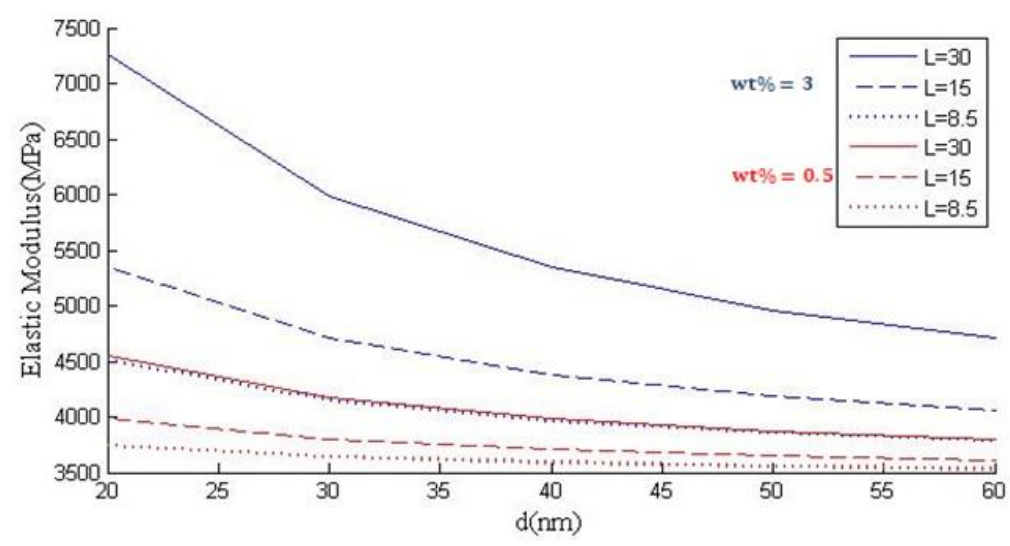

Fig. 5. The efficient of CNTs weight percent, length and diameter of CNT on elastic modulus of nanocomposite. 


\section{CONCLUSION}

To verify the predictions of the new model we used experimental data and some well-known theories. The correlation of the experimentally obtained elastic modulus showed a good agreement with this model. This model is suitable to predict the elastic modulus of nanocomposite with polymer matrix. The effects of length, diameter of CNT and CNT weight percent on the mechanical properties were investigated. Increasing the elastic modulus of nanocomposite is related to increasing on CNTs weight percent and length of CNT and decreasing the diameter of CNT. Through predicting error of elastic modulus by using the other theories, errors at high volume fraction at most of models were more than $10 \%$, while by using this new model we improved the results and error has been decreased.

\section{REFERENCES}

[1] H. Baharvandi, M. Saeedi Heydari, N. Kordani, M. Alebooyeh, M. AlIZADEH, P. KHAKSARI (2017) Characterization of the rheological and mechanical properties of shear thickening fluid-coated Twaron ${ }^{\circledR}$ composite. The Journal of the Textile Institute 108 397-407.

[2] H. Baharvandi, M. Alebooyeh, M. Alizadeh, P. Khaksari, N. Kordani (2016) Effect of silica weight fraction on rheological and quasi-static puncture characteristics of shear thickening fluid-treated Twaron ${ }^{\circledR}$ composite. Journal of Industrial Textiles 46 473-494.

[3] I. Petrova, E. Ivanov, R. Kotsilkova, Y. Tsekov, V. Angelov (2013) Applied Study on Mechanics of Nanocomposites with Carbon Nanofillers. Journal of Theoretical and Applied Mechanics 43 67-76.

[4] G. Nikolova, J. Ivanova, Z. Mroz (2006) Modelling of thermally induced progressive delamination in a two-plate structure. Journal of Theoretical and Applied Mechanics 36 71-92.

[5] N. Kordani, A. SADOUGH (2014) Different method to make laminates by shear thickening fluid. Science and Engineering of Composite Materials (SECM) 21 421-425.

[6] H. Baharvandi, M. Alebooyeh, M. Alizadeh, M. Saeedi Heydari, N. KorDANI, P. KHAKSARI (2016) The influences of particle-particle interaction and viscosity of carrier fluid on characteristics of silica and calcium carbonate suspensions-coated Twaron ${ }^{\circledR}$ composite. Journal of Experimental Nanoscience 11 550-563.

[7] A. Fereidoon, N. Kordani, M.G. Ahangari, M. Ashoory (2011) Damping augmentation of epoxy using carbon nanotubes. International Journal of Polymeric Materials 60 11-26.

[8] C. S. JARALI (2017) Modelling of the interfacial damping due to nanotube agglomerations in nanocomposites. Smart Structures and Systems 19 57-66.

[9] J. Ivanova, V. Valeva, Z. Mroz (2006) Mechanical modelling of the delamination of bi-material plate structure. Journal of Theoretical and Applied Mechanics 36(4) 03. 
368 New Theory of the Elastic Modulus of Carbon Nanotube Based-Composites

[10] S. IIJIMA (1991) Helical microtubules of graphitic carbon. Nature (London) 354 56-58.

[11] T. NATSUKI, K. TANTRAKARN, M. ENDO (2004) Effects of carbon nanotube structures on mechanical properties. Applied Physics A 79 117-124.

[12] R. Khare, S. Bose (2005) Carbon nanotube based composites - a review. Journal of Minerals and Materials Characterization and Engineering 4 31-46.

[13] S. Deepak, Q. Dong, J. Gregory, Wagner, Y.U. Min Feng, R.S. Ruoff, et AL. (1986) "Handbook of Nanotechnology".

[14] P.J.F. HARRIS (1999) "Carbon Nanotubes and Related Structures: New Materials for the 21st Century". Cambridge University Press, Cambridge, UK, p. 9.; https://doi.org/10.1017/CBO9780511605819.

[15] V. Mittal (ED.) (2010) "Polymer Nanotube Nanocomposites". John Wiley \& Sons Ltd.

[16] M.R. BAgheri, N. Kordani, S.A. SAdough VANini (2018) Multi-scale simulation of double-walled carbon nanotube-reinforced composites. Iranian Journal of Science and Technology. Transaction A: Science $\mathbf{4 2}$ 1177-1184.

[17] J.C. HALPIN, S.W. TSAI (1967) Environmental factors in composite materials design. AFML-TR 67-423.

[18] J.C. Halpin, J.L. Kardos (1976) The Halpin-Tsai equations: A review. Polymer Engineering and Science 16 344-352.

[19] K.T. Kashyap, P.G. Koppad, K.B. Puneeth, H.R. Aniruddha Ram, H.M. MALLIKARJUNA (2011) Elastic modulus of multi-walled carbon nanotubes reinforced aluminium matrix nanocomposite. Computational Materials Science 50 2493-2495.

[20] H.L. Cox (1952) The elasticity and strength of paper and other fibrous materials. British Journal of Applied Physics 3 72-79.

[21] M.K. YeH, N.H. TAI, J.H. LIU (2006) Mechanical behavior of phenolic-based composites reinforced with multi-walled carbon nanotubes. Carbon 44 1-9.

[22] E.T. Thostenson, T.W. Chou (2003) On the elastic properties of carbon nanotubebased composites: Modeling and characterization. Journal of Physics D: Applied Physics 36 573-585.

[23] C.L. TUCKER (1999) Stiffness predictions for unidirectional short-fiber composites: Review and evaluation. Composites Science and Technology 59 655-671.

[24] P.T. Crutis, M.G. Bader, J.E. Bailey (1978) The stiffness and strength of a polyamide thermoplastic reinforced with glass and carbon fibers. Journal of Materials Science 13 377-390.

[25] Y. LU (2002) Mechanical properties of random discontinuous fiber composites manufactured from wetlay process. PhD Thesis, Blacksburg, Virginia, http://citeseerx.ist.psu.edu/viewdoc/download?doi=10.1.1.561.8559\&rep=rep1\&type=pdf.

[26] A. Montazeri, J. Javadpour, A. Khavandi, A. Tcharkhtchi, A. Mohajeri (2010) Mechanical properties of multi-walled carbon nanotube/epoxy composites. Materials \& Design 31 4202-4208. 